\title{
Técnica e saberes tradicionais na formação profissional do Tecnólogo em Construção Civil $^{1}$
}

\author{
Technique and traditional knowledge in the professional graduation of the Technologist in Civil \\ Construction
}

Técnica y conocimientos tradicionales en la formación profesional del Tecnólogo en Construcción Civil

Recebido: 27/04/2021 | Revisado: 05/05/2021 | Aceito: 06/05/2021 | Publicado: 15/05/2021

\author{
Luiz Eduardo Camargo dos Santos Cecilio \\ ORCID: https://orcid.org/0000-0001-5659-0191 \\ Centro Estadual de Educação Tecnológica Paula Souza, Brasil \\ E-mail: luizecsc@gmail.com \\ Emerson Freire \\ ORCID: https://orcid.org/0000-0001-5449-2002 \\ Centro Estadual de Educação Tecnológica Paula Souza, Brasil \\ E-mail: freire.emerson@uol.com.br
}

\begin{abstract}
Resumo
Buscando entender melhor a relação histórica do ser humano com a técnica, e indo além da dicotomia que sugere o par teoria e prática no âmbito da educação, o presente artigo procura trazer, passando pelo pensamento do filósofo francês Gilbert Simondon e do educador Jarbas Novelino Barato, cada qual no seu devido contexto, reflexões sobre o processo de ensino e aprendizagem em cursos de educação profissional e tecnológica. Trata-se de uma pesquisa bibliográfica e documental que busca discutir a relevância e as contribuições dos saberes tradicionais na trajetória de construção do perfil de profissionais Tecnólogos em Construção Civil, por sua vez diretamente ligados a cultura e ao pensamento contemporâneo. O recorte dessa pesquisa está centrado no estudo de documentos relacionados aos cursos de Tecnologia da Construção Civil e na análise da formação desses profissionais. Para tanto, pretende-se conceituar os termos destacados e relacioná-los à aspectos concretos do tipo de curso em questão.

Palavras-chave: Ensino; Educação profissional e tecnológica; Cultura e técnica; Saberes tradicionais; Tecnólogo em construção civil.
\end{abstract}

\begin{abstract}
Seeking to better understand the historical relationship of the human being with the technique, and going beyond the dichotomy that suggests the pair theory and practice in the scope of education, this article seeks to bring, through the thought of the French philosopher Gilbert Simondon and the educator Jarbas Novelino Barato, each in its own context, reflections on the teaching and learning process in professional and technological education courses. This is a bibliographic and documentary research that seeks to discuss the relevance and contributions of traditional knowledge in the trajectory of building the profile of professional Technologists, in turn directly linked to culture and contemporary thought. The focus of this research is centered on the study of documents related to Civil Construction Technology courses and on the analysis of the training of these professionals. Therefore, it is intended to conceptualize the highlighted terms and relate them to concrete aspects of the type of course in question.

Keywords: Teaching; Professional and technological education; Culture and technique; Traditional knowledge; Technologist in civil construction.

\section{Resumen}

Buscando comprender mejor la relación histórica del ser humano con la técnica, y yendo más allá de la dicotomía que sugiere la teoría y la práctica de la pareja en el ámbito de la educación, este artículo busca acercar, a través del pensamiento del filósofo francés Gilbert Simondon y el El educador Jarbas Novelino Barato, cada uno en su propio contexto, reflexiones sobre el proceso de enseñanza y aprendizaje en los cursos de educación profesional y tecnológica. Se trata de una investigación bibliográfica y documental que busca discutir la relevancia y aportes del conocimiento tradicional en la trayectoria de construcción del perfil professional de los Tecnólogos en Construcción
\end{abstract}

\footnotetext{
${ }^{1}$ Esse texto surge no âmbito das reflexões de uma pesquisa de mestrado em andamento no Centro Estadual de Educação Tecnológica Paula Souza, no programa de Gestão de Desenvolvimento da Educação Profissional. Uma versão primária dessa pesquisa foi apresentada em evento interno do programa de mestrado.
} 
Civil, directamente vinculados a la cultura y al pensamiento contemporáneo. El foco de esta investigación se centra en el estudio de documentos relacionados con los cursos de Tecnología de la Construcción Civil y en el análisis de la formación de estos profesionales. Por tanto, se pretende conceptualizar los términos resaltados y relacionarlos con aspectos concretos del tipo de curso destacado.

Palabras clave: Enseñanza; Educación profesional y tecnológica; Cultura y técnica; Conocimiento tradicional; Tecnólogo em construcción civil.

\section{Introdução}

Uma situação cotidiana observada durante a experiência de um dos autores deste artigo, como professor do Centro Universitário Belas Artes de São Paulo, no curso de Arquitetura e Urbanismo, é a realização de algumas aulas que acontecem em um laboratório chamado "canteiro de obras". Nelas, englobam-se diversos temas ligados ao universo da construção civil como sistemas construtivos, instalações prediais, estruturas, vedações e acabamentos, e são ministradas pelo professor sempre acompanhado de um técnico do laboratório. O profissional contratado para essa função de técnico é, geralmente, um mestre de obras com experiência de trabalho no mercado. A contribuição do mestre de obras no exercício do ensino das técnicas naquele contexto é muito relevante. Apesar de não ter formação acadêmica, teórica ou formal, existe um tipo de execução de atividades desenvolvidas em sua experiência no mundo do trabalho que ele é capaz de ensinar, contemplando certas especificidades dos saberes técnicos.

O encontro do profissional dotado de um conhecimento que, segundo Barato (2003), pode ser chamado de saber do trabalho, e que aqui convém chamar de tradicional (ou "popular"), ou seja, aquele que não foi validado cientificamente, com os saberes acadêmicos e científicos do professor, é o ponto inicial dessa discussão. A ideia de complementação entre o conhecimento obtido de maneira empírica, baseado na experiência do cotidiano do trabalho, e conhecimentos teóricocientíficos a respeito de um mesmo assunto, porém advindos de formações distintas, instiga reflexões sobre o processo de aprendizagem em cursos de formação profissional e tecnológica. Trata-se de buscar um melhor entendimento da relação entre o homem e a técnica para além da cômoda dicotomia teoria e prática, uma vez que a atividade técnica não se resume à uma teorização econômica e nem mesmo se equivale ao trabalho especialista dissociado da cultura e do pensamento.

É nesse sentido que o filósofo francês, Gilbert Simondon (1969, 1964, 1989), propõe o desenvolvimento de uma cultura técnica de fato, que se contraponha ao que ele chama de "tecnicismo intemperante", considerando essa relação, esse diálogo entre homem, ferramentas e máquinas, nos níveis dos esquemas de funcionamento destas, onde aparece o que ele denomina intuição técnica e possibilita a ampliação do aprendizado e do conhecimento bem como, em consequência, do processo inventivo. Como salienta o filósofo:

Saber utilizar uma ferramenta não é somente adquirir a prática dos gestos necessários; é, também, saber reconhecer através dos sinais que vêm ao homem pela ferramenta a forma da matéria que se desenvolve, o lugar preciso que a ferramenta ataca (Simondon, 1964, p. 52, tradução livre nossa)

Essa percepção implícita das informações e dos sinais envolvidos nessa relação, acontece habitualmente na resolução de problemas técnicos que se dão no fazer cotidiano em diversas áreas de atuação e que se valem de conhecimentos que não se apoiam imediatamente à normatividade acadêmica e científica.

Aqui, portanto, a partir de um breve referencial teórico e de alguns documentos pertinentes, pretende-se observar a relevância desses conhecimentos ditos tradicionais para determinadas áreas, mais especificamente para a formação técnica/tecnológica em construção civil. Devido ao seu caráter ainda predominantemente artesanal, existem questões técnicas nessa área, bem como em muitas outras, que são didaticamente melhores traduzidas através de saberes do fazer (ou do trabalho), sem que sejam desconsideradas quaisquer novas tecnologias que estejam sendo desenvolvidas nesse ramo de atividade, que aliás, muitas vezes, se desenvolvem justamente com a colaboração de conhecimentos ditos tradicionais. 


\section{Metodologia}

Para analisar as contribuições dos saberes tradicionais na formação do tecnólogo em construção civil, foi escolhido como método de pesquisa fazer uma discussão teórico-referencial sobre as origens conceituais das técnicas e seus desdobramentos no tempo e a influência de um conjunto de conhecimentos ditos tradicionais em uma formação acadêmica na mesma área. No capítulo seguinte, portanto, será iniciada a discussão baseando-se em escritos de autores das áreas da educação, da filosofia, e da antropologia. Em seguida, a pesquisa apresentará uma análise documental, a partir das ideias do referencial teórico, e um breve estudo do projeto pedagógico do curso superior de Tecnologia da Construção Civil Modalidade: Edifícios da Fatec-SP. Essa análise visa elucidar onde e como os saberes tradicionais encontram consonância com aspectos descritos em ementas e objetivos da formação em disciplinas do curso. Serão analisados, também, aspectos e atribuições profissionais dos trabalhadores dessa área e a relação da formação com os conhecimentos tradicionais, à luz dos autores e pensadores selecionados. Portanto, será feita uma pesquisa de natureza exploratória descritiva, que, de acordo com Sampieri (2013) são aquelas que se propõe a estudar temas ainda pouco abordados em estudos científicos, podendo utilizar como ferramentas para obtenção de dados entrevistas, documentos, bibliografia relacionada. A pesquisa tem abordagem qualitativa

\section{Cultura, Técnica e Saberes Tradicionais}

É muito conhecido o antigo anseio dos seres humanos pelo domínio da natureza, mais por sobrevivência do que por vontade, é bem verdade. Em tempos primitivos, sobreviver quase sempre dependia da forma como as populações confeccionavam suas ferramentas e seus objetos, como construíam seus abrigos e como ocupavam os espaços. A relação homem-natureza foi moldada juntamente com a técnica, em grande parte por necessidades humanas, ou seja, a própria condição humana pode ser considerada a partir de uma perspectiva de sua relação com técnica.

Autores como Flusser (2007), por exemplo, propõem questionarmos nossa identificação enquanto espécie, privilegiando com mais atenção o termo Homo faber em relação à designação Homo sapiens. Quando o Homem passa a se apresentar enquanto uma espécie que tem por característica fundamental a fabricação de artefatos, isso também o coloca em uma rota de pensamento em que a história da humanidade se confunde com a história das técnicas. A capacidade de domar a natureza e transformar ação em invenção foi, possivelmente, um primeiro lampejo de inteligência dos seres humanos. Segundo Flusser:

Uma vez que as mãos humanas, assim como as mãos dos primatas, são órgãos próprios para girar coisas (e entenda-se $\mathrm{o}$ ato de girar, virar, como uma informação herdada geneticamente), podemos considerar as ferramentas, as máquinas e os eletrônicos como imitações das mãos, como próteses que prolongam o alcance das mãos[...] (Flusser, 2007, p. 36).

Ao fazer essa analogia, Flusser traz à superfície a necessidade de se olhar com atenção para os objetos (ou seres) técnicos e suas funções, e o quanto de humano há neles. A partir desse exercício, a tendência é notar que as bordas que separam homem e natureza revelam-se borradas, inexatas.

Apesar de a noção exposta por autores como Flusser (2007), de que a associação homem-técnicas-mundo pode parecer automática, o pensamento de Simondon denuncia uma recorrente contraposição construída entre cultura e técnica, explicitando a incoerência deste embate. Ou seja, para ele há uma insistente recusa por parte da cultura em reconhecer o objeto técnico como parte naturalmente integrante dos processos do fazer tecnológico, resultando em uma oposição entre homem e máquina, em que se perde a noção da técnica como mediadora entre homem e mundo, aparecendo mais como apêndice, com um modo de existência não próprio, somente vista para fins utilitários e de consumo, próprios da vertente tecnicista. Para 
Simondon essa oposição ente cultura e técnica é falsa e sem fundamento, pois a ligação homem-técnica remete à ideia de gênese, ao início do processo inventivo, algo que transcende o meramente econômico e encontra-se mais próximo à relação com os instintos, com a intuição.

Simondon auxilia em avançar na formação de um pensamento contemporâneo acerca das técnicas e da tecnologia, que não deixa de considerar o avanço tecnológico, das máquinas informacionais e da cibernética, mas que busca um deslocamento de um sentido utilitário sobre elas para uma compreensão genética, passando a enxergar o objeto técnico não mais como apenas um "instrumento, adjuvante ou produto do trabalho" (Simondon, 2007, p. 257).

Com essa perspectiva presente na filosofia de Simondon, quando relacionada aos saberes tradicionais e no caminho a percorrer até certa formalização da transferência de conhecimentos técnicos, percebe-se de imediato, entre outros pontos, o desafio no ambiente escolar de incorporar atividades que desenvolvam os saberes técnicos com a atenção necessária, contemplando sua complexidade. Pensar sobre como a execução de atividades (produtivas, criativas etc.), aproximando trabalho, técnica e educação, é essencial para moldar ações propositivas sobre o ensinar e, principalmente, sobre o aprender a trabalhar. Barato (2003), em sua tese de doutorado, reivindica que a técnica é um saber com status epistemológico próprio, e vai além ao afirmar que "é preciso conhecer bem as especificidades do fazer-saber para propor modos de organizar informações (situações de ensino) que possam favorecer a aprendizagem (a constituição do conhecimento pertinente)" (Barato, 2003, p. 3).

A área da construção civil, e outras como foi dito, é composta também por uma série de conhecimentos tradicionais que foram sistematizados e evoluíram ao longo do tempo. Da pedra lascada à automação, da terra crua ao concreto armado, permeada por técnicas e tecnologias que acompanharam o desenvolvimento da humanidade na busca por atender algumas de suas necessidades. A construção civil é, por definição, uma ciência do fazer. E, nesse sentido, o aprender a fazer é, antes de tudo, um exercício. Mas não só isso. Disse Aristóteles (1991) que "as coisas que temos de aprender antes de poder fazê-las, aprendemo-las fazendo". E, para ilustrar seu pensamento, afirmou que "homens tornam-se arquitetos construindo". Em outro contexto, o educador e filósofo venezuelano Simon Rodriguez dizia que uma criança aprende mais "em um momento, esculpindo um palito, que em dias inteiros, conversando com um professor que lhe fala de abstrações superiores à sua experiência” (Rodriguez, 2016, p. 173). Ele acreditava que lidar com as coisas constitui a primeira parte da educação e lidar com quem as possui, a segunda. Esses são pontos interessantes pois trazem dois novos elementos para o centro da discussão sobre o ensino e a aprendizagem das técnicas: a experiência e os objetos.

O filósofo e pedagogo espanhol Jorge Larrosa (2015, p. 18), afirma que "a experiência é o que nos passa, o que nos acontece, o que nos toca". Se reconhecermos a experiência como conhecimento prático, vivido, e como potencial fonte de aprendizagem, será necessário admitir que nosso modo de estar, ser e de interagir com as coisas, constitui parte fundamental desse mesmo processo. O sentido empregado aqui, portanto, é o que entende a experiência como uma relação com o mundo em que estamos inseridos. Contreras e Lara (2010), na introdução de seu livro intitulado Investigar la experiencia educativa apontam que:

É condição da experiência estar envolvido em um fazer, em uma prática, estar imerso em um mundo que chega a nós, que nos envolve, que nos compromete ou, às vezes, exige de nós ou nos impõe. (Contreras, Lara, 2010, p. 25-26)

É próprio das atividades do fazer, criar sentimentos, sensações, incômodos, prazeres, que podem ser convertidos em conhecimentos se assim, a partir da experiência, forem incorporados à ação. Isso não significa, porém, que a experiência está para a aprendizagem exclusivamente no campo da percepção e do que nos toca. Ou, como bem aponta Richard Sennett na conclusão de seu livro O Artífice, a experiência não mora apenas na "subjetividade que prospera no puro e simples processo de sentir" (Sennett, 2019, p. 322). Ele reivindica, porém, um olhar para a experiência como ofício e fala, inclusive, em "técnicas de experiência", sugerindo que nos concentremos nas formas e nos procedimentos. Ou seja, para ele a maneira como 
vivenciamos as experiências está diretamente relacionada à maneira com que nossos corpos se relacionam com o mundo e com a capacidade que temos de gestão dessas relações. Numa acepção abertamente pragmatista, afirma que "aquilo que somos deriva diretamente do que nossos corpos são capazes de fazer." E complementa dizendo que "existem consequências sociais integradas à estrutura e ao funcionamento do corpo humano, como acontece na ação da mão humana” (Sennett, 2019, p, 323).

A relação das técnicas com a formalização dos conhecimentos dessa área é observada no resgate histórico que Milton Vargas faz em seu livro "História da Técnica e da Tecnologia no Brasil”. O autor traz pontos importantes sobre a evolução da pesquisa tecnológica no país e, ao citar determinado artigo de um professor da Escola Politécnica de São Paulo escrito no início do século XX, afirma que "por tecnologia entendia-se, já na época, o estudo dos materiais e processos utilizados para realizar uma obra de engenharia" (Vargas, 1994, p. 213). Em seguida complementa e propõe sua própria definição para tecnologia como sendo "o estudo ou tratado das aplicações de métodos, teorias, experiências e conclusões das ciências ao conhecimento dos materiais e processos utilizados pela técnica" e conclui afirmando que apesar de existir uma tecnologia implícita em áreas como engenharia e arquitetura, não devemos confundir sua função com a da função da tecnologia pois apesar de tais profissões contemplarem também "a arte de construir obras, fabricar produtos, ou cultivar a natureza" (Vargas, 1994, p. 213), a tecnologia é mais ampla e não visa nenhuma área em particular.

Simondon (1969) dirá que não é de maneira direta, por dedução, que uma descoberta científica se torna um dispositivo técnico ou uma tecnologia específica. Embora ela, a descoberta científica, traga condições novas para a pesquisa técnica, é ainda necessário que um esforço de invenção se realize para que o objeto ou a nova técnica apareça, ou dito de outra forma:

É preciso que o pensamento científico se torne operatório ou apoio de esquemas operatórios. Ao contrário, o que se pode chamar de tecnologia pura está no ponto de interconexão de várias ciências e também de vários campos técnicos tradicionais distribuídos entre várias profissões (Simondon, 1969, p. 218 - tradução livre nossa).

É nesse ponto que as contribuições dos saberes tradicionais de várias profissões se fazem presentes, muitas vezes de forma decisiva, pois lidam com os esquemas de ação e de funcionamento diretamente, com a tecnicidade dos elementos no nível entre o abstrato e o concreto, fazendo uso de um conjunto de eventos psíquicos, perceptivos e somáticos particulares à atividade profissional envolvida. É quando a partir do conhecimento intuitivo se alcança a imaginação técnica, considerada "uma sensibilidade particular à tecnicidade dos elementos [...], que permite a descoberta de montagens possíveis" (Simondon, 1969, p. 74 - tradução livre nossa), ou seja, o processo inventivo. A imaginação técnica como capacidade de perceber nos objetos certas qualidades que "não são práticas, nem diretamente sensoriais nem inteiramente geométricas, que não referem à matéria pura nem a forma pura, mas que estão no nível intermediário dos esquemas” (p. 74). Portanto, muitas vezes, os saberes tradicionais se complementam aos científicos e acadêmicos nesse nível da atividade técnica, entre o abstrato e o concreto, na resolução de problemas que envolvem o meio profissional associado.

\section{A Formação do Tecnólogo em Construção Civil}

De acordo com o artigo $3^{\circ}$ da Resolução no 313, de 26 de setembro de 1986, do CONFEA (Conselho Federal de Engenharia e Agronomia):

São atribuições dos Tecnólogos, em suas diversas modalidades, para efeito do exercício profissional, e da sua fiscalização, respeitados os limites de sua formação:

1) elaboração de orçamento;

2) padronização, mensuração e controle de qualidade;

3) condução de trabalho técnico; 

4) condução de equipe de instalação, montagem, operação, reparo ou manutenção;
5) execução de instalação, montagem e reparo;
6) operação e manutenção de equipamento e instalação;
7) execução de desenho técnico.

Analisando a gama de atribuições legais conferidas aos tecnólogos, vemos que há um predomínio de atividades ou práticas que podem ser lidas como atividades técnicas, no sentido mais amplo. Espera-se, então, como em qualquer curso na área de educação profissional e tecnológica, que durante as aulas assistidas pelos alunos ao longo de sua formação, estejam contemplados todos, ou a maior parte, os itens descritos acima, dentro de suas especificidades. A consonância entre a atribuição legal e a formação revela-se mais forte, mesmo que ainda de forma documental, quando é lido no Projeto Pedagógico do Curso Superior de Tecnologia da Construção Civil - Modalidade: Edifícios da Fatec-SP o tópico que descreve o perfil dos profissionais:

[...] Tem competência para elaborar orçamentos e memoriais descritivos, especificar materiais, realizar controle de qualidade, conduzir trabalhos técnicos em geral e gerenciar equipes de trabalhos. [...] está capacitado a executar desenhos técnicos, dimensionar instalações [...] conhece os materiais e as técnicas das construções e os equipamentos. Pode dedicar-se ao ensino, à pesquisa aplicada, à realização de vistorias, a avaliações e à elaboração de laudos técnicos dentro do seu campo profissional. (CEETEPS)

Ensinar exatamente aquilo que se espera que os profissionais estejam habilitados a executar parece uma obviedade, porém o aspecto que se espera destacar com essas informações é outro. Como o objetivo aqui é investigar a contribuição dos saberes tradicionais na formação acadêmica do tecnólogo em construção civil, é interessante identificar onde esses conhecimentos encontram eco dentro da legislação, no plano pedagógico e nas ementas das disciplinas do curso. Se estão indo daí para as salas de aula e laboratórios integralmente foge ao escopo deste artigo, mas trata-se de assunto fundamental a ser investigado em outros trabalhos.

Ainda de acordo com o Projeto Pedagógico do Curso (PPC), em questão, são descritas habilidades e competências a serem adquiridas em cada componente curricular, ou disciplina. Nota-se que características que podem ser atribuídas aos ditos saberes tradicionais estarão presentes indiretamente nos textos e descrições das disciplinas. Um exemplo que ilustra essa afirmação é quando, na descrição de competências atribuídas à disciplina "Práticas Construtivas - Alvenarias" encontram-se coisas como "Coordenar a execução" ou "Fiscalizar a execução de serviços". Aqui a formação tecnológica, em tese, não habilita para a execução, para a construção propriamente dita, contudo oferece conhecimento intelectual acerca daquela tarefa, ao mesmo tempo em que o PPC explicita que esse egresso "conhece os materiais e as técnicas das construções e os equipamentos". O êxito na construção depende, portanto, e na mesma medida, do conhecimento do fazer adquirido comumente de forma empírica, na prática, pelo profissional que vai executar a técnica aliado à formação acadêmica do tecnólogo, validada cientificamente. Os conhecimentos revelam-se complementares. No limite, então, não haveria relação de subordinação da atividade prática (técnica) à teoria (ciência).

Partindo do pressuposto conceituado por Vargas (1994), de que a tecnologia e, consequentemente, a técnica têm função própria, é possível notar que as definições acima encontram correspondência nas obras de Simondon e Barato. Barato (2003) reivindicando o fazer como uma forma de conhecimento com estrutura própria, também classifica determinados saberes como processos. E, buscando deixar sua ideia mais clara, diz que o "saber processual, nos contextos em que faz sentido e é necessário, funciona como um solo em uma sinfonia: é predominante e determina os demais tipos de saberes que com ele se relacionam em certas execuções” (Barato, 2003, p. 10). Se há essa conexão entre os demais saberes como o saber solo processual nas execuções, ou seja, nos esquemas de funcionamento, ela não é menos verdadeira quando se pensa um acoplamento positivo (não positivista) entre homem-máquina-ferramenta. E é curioso que, neste caso, Simondon faça alusão 
também ao universo musical, mais especificamente do papel do homem enquanto uma espécie de maestro:

Longe de ser o vigia de um grupo de escravos, o homem é o organizador permanente de uma sociedade dos objetos técnicos que precisam dele como os músicos precisam do maestro. O maestro da orquestra só pode reger os músicos porque ele interpreta, como eles e tão intensamente quanto todos eles, a peça executada. Ele acalma ou apressa os músicos, mas é também acalmado e apressado por eles; de fato, através dele, a orquestra acalma e apressa cada músico. Ele é para cada um deles a forma movente e atual do grupo em sua existência presente; ele é o intérprete mútuo de todos com relação a todos. Assim, o homem tem por função ser o coordenador e o inventor permanente das máquinas que estão à sua volta. Ele está entre as máquinas que operam com ele (Simondon, 2008, p. 171).

Há assim uma interconexão entre os saberes processuais, próximo ao solo em uma sinfonia, como sugere Barato (2003), e o aprendizado constante como coordenador e inventor de técnicas e máquinas, como diz Simondon (1969). Trata-se de um domínio do fazer-saber que pode determinar o caminho do ensino, cuja função fundamental é, para o filósofo, promover uma "tomada de consciência do sentido dos objetos técnicos" (p. 9) pela cultura, em que Simondon projeta um lugar privilegiado ao tecnólogo:

Essa tomada de consciência exige a existência, ao lado do psicólogo e do sociólogo, do tecnólogo ou mecanólogo. Além disso, os esquemas fundamentais de causalidade e de regulação que constituem uma axiomática da tecnologia devem serem ensinadas de maneira universal, como são ensinados os fundamentos da cultura literária. A iniciação às técnicas deve ser colocada sobre o mesmo plano que a educação científica; ela é tão desinteressada quanto a prática das artes, e domina tanto as aplicações práticas quanto a física teórica; ela pode atingir o mesmo grau de abstração e de simbolismo (Simondon, 2008, p. 172)

Ao sobrepor o desenvolvimento teórico e filosófico da técnica e dos saberes tradicionais à aspectos documentais e institucionais da formação do tecnólogo, nota-se que há correspondências e que são elementos que podem caminhar juntos na promoção de uma cultura técnica, no sentido conferido por Simondon. Quando o autor fala em uma tomada de consciência da realidade técnica pelos homens, a fim de introduzi-la na cultura, é sobre o sentido de agrupar e, de maneira generalista, buscar o sentido no fazer da técnica. No contexto da Educação Profissional e Tecnológica, voltado para sua inserção na sociedade, seria interessante retomar essa função do tecnólogo, inclusive em sua relação com o mercado (Freire, 2012), nesse sentido: a leitura da complexidade dos objetos técnicos e a devolução do seu caráter geral à cultura. No âmbito da construção civil, os saberes tradicionais funcionam como o elo entre a técnica propriamente dita e as práticas de ensino sob elas debruçadas.

\section{Considerações Finais}

Para além de toda a terminologia utilizada para descrever e classificar as atividades desenvolvidas nos cursos de EPT, em especial na formação do Tecnólogo em Construção Civil, e, sem deixar de considerar as mudanças e avanços tecnológicos no tempo e sua influência nos meios de execução de trabalhos nessa área, ainda é visível a influência dos saberes tradicionais e o peso do ensino de algumas técnicas, visando uma formação integral destes profissionais. Casos como a do mestre de obras / técnico de laboratório citada na introdução deste artigo são comuns e evidenciam que, ao reconhecer a técnica como um saber inerente ao ser humano, passível de ser trabalhado e aperfeiçoado, abrimos caminho para um entendimento maior do trabalho como um fazer dotado de inteligência e percepção próprias, antes de ser academicamente formalizado e independente dessa condição.

Consultando as obras do filósofo francês Gilbert Simondon e do educador Jarbas Novelino Barato em seus escritos sobre o sentido dos objetos técnicos e sobre as especificidades do saber técnico, respectivamente, é possível afirmar que a realização de estudos e reflexões sobre a técnica no âmbito da Educação Profissional e Tecnológica (EPT) se fazem cada vez mais pertinentes. Simondon e Barato são importantes para as discussões deste artigo pois dão subsídios filosóficos e teóricos sobre: a) a técnica enquanto parte material de determinada arte ou ciência e o modo de existir dos seres técnicos e b) sobre os desdobramentos das técnicas e conhecimentos tradicionais em ambientes e situações de ensino no âmbito da educação 
profissional e tecnológica.

Trazer tais contribuições à luz das discussões que permeiam a organização dos cursos de formação profissional e tecnológica, tem o sentido de contrapor um caráter simplista na abordagem do ensino das técnicas, ora focados em uma clássica pedagogia tecnicista que relega os processos educativos a meras atividades objetivas e processuais, ora ignorando por completo suas características específicas em detrimento de uma constante teorização. Essa tendência aos extremos desconsidera ao mesmo tempo a significação e a real contribuição dos saberes do fazer para uma formação ampla de profissionais nos cursos de EPT.

Foge ao escopo deste artigo, porém seria interessante que, em pesquisas futuras, fosse investigado de qual maneira esse tipo de conhecimento, aqui chamado de saberes tradicionais, chega até os alunos em sala de aula. Quais elementos trazem, para o dia a dia de uma formação profissional e tecnológica, os conteúdos do saber-fazer? Para que a partir desse tipo de questionamento sejam elaboradas ou aprimoradas situações e metodologias de ensino que contemplem tais saberes, e que assim contribuam para a formação profissional, sugere-se um maior aprofundamento de pesquisas na área das práticas de ensino.

\section{Referências}

Aristóteles (1991). Ética a Nicômaco; Poética / Aristóteles; seleção de textos de José Américo Motta Pessanha. — 4. ed. — São Paulo: Nova Cultural.

Barato, J. N. (2003). A técnica como saber: investigação sobre o conteúdo do conhecimento do fazer / Jarbas Novelino Barato. -- Campinas, SP: [s.n.]

Barato, J. N. (2002). Escritos sobre tecnologia educacional \& educação profissional. São Paulo: Editora Senac.

Centro Estadual de Educação Tecnológica Paula Souza (Ceeteps). Faculdade de Tecnologia de São Paulo. Projeto pedagógico do Curso Superior de Tecnologia em Construção Civil - Modalidade: Edifícios. São Paulo, [S.I.]. http://www.fatecsp.br/paginas/proj_ped_edificios.pdf

Conselho Federal De Engenharia, Arquitetura e Agronomia (Confea). Resolução n ${ }^{\circ} 313$, de 23 de setembro de 1986. Dispõe sobre o exercício profissional dos Tecnólogos das áreas submetidas à regulamentação e fiscalização instituídas pela Lei nº 5.194, de 24 DEZ 1966, e dá outras providências. Diário Oficial da União: seção I - Págs. 5.157 a 15.159.

Contreras, J. \& Lara, N. P. (2010). (Comp.). Investigar la experiencia educativa. Madrid: Morata.

Cruz, C. (2015). Avanço técnico e humanização em Gilbert Simondon. Scientiae Studia, v. 13, n. 2, p. 431-8.

Flusser, V. (2017). O Mundo Codificado: por uma filosofia do design e da comunicação. São Paulo: Ubu Editora.

Freire, E. (2012) Tecnólogo e Mercado: uma relação a ser revisitada. Educação Tecnológica reflexões, teorias e práticas. Jundiaí, p. 103-15. Paco Editorial.

Larrosa, J. (2015). Tremores: escritos sobre experiência. - $1^{\mathrm{a}}$ ed. - Belo Horizonte: Autêntica Editora.

Rodriguez, S. (2016). Inventamos ou erramos. / Simón Rodriguez. - $1^{\text {a }}$ ed. - Belo Horizonte: Autêntica Editora.

Sampieri, R. H. \& Collado, C. F. \& Lucio, M. P. B. (2013). Metodologia de pesquisa. Porto Alegre: Penso.

Sennet, R. (2019). O artífice. $-6^{\mathbf{a}}$ ed. - Rio de Janeiro: Record.

Simondon, G. (2007). El modo de existência de los objetos técnicos.1 ed. - Buenos Aires: Prometeo Libros.

Simondon, G. (1964) L'individu Et Sa Genèse Physico-Biologique: L'individuation À La Lumière Des Notions De Forme Et D'information. Paris: Press Universitaires de France.

Simondon, G. (1969). Du Mode D'existence Des Objets Techniques. Paris: Aubier - Montaigne

Simondon, G. (2020). Do modo de existência dos objetos técnicos. - $1^{\text {a }}$ ed. - Rio de Janeiro: Contraponto

Simondon, G. (2008). Cultura e Técnica. Trad. Pedro Peixoto Ferreira e Christian Pierre Kasper. Nada, Lisboa, n. 11, p. 168 -175.

Simondon, G. (2017). Sobre la técnica: 1953-1983. - $1^{\text {a }}$ ed. - Ciudad Autónoma de Buenos Aires: Cactus.

Vargas, M. (1994). (Org.). História da técnica e da tecnologia no Brasil. Editora da Universidade Estadual Paulista: Centro Estadual de Educação Tecnológica Paula Souza. São Paulo, 1994. 